\title{
Impact of Climate Change on Species Distribution and Carbon Storage of Agroforestry Trees on Isolated East African Mountains
}

\author{
Dickens Odeny',2 (D), Faith Karanja², Geoffrey Mwachala1, Petri Pellikka ${ }^{3,4}$, Rob Marchant ${ }^{5}$ \\ ${ }^{1}$ Center for Biodiversity, National Museums of Kenya, Nairobi, Kenya \\ ${ }^{2}$ Department of Geospatial and Space Technology, The University of Nairobi, Nairobi, Kenya \\ ${ }^{3}$ School of Remote Sensing and Geomatics Engineering, Nanjing University of Information Science and Technology, Nanjing, China \\ ${ }^{4}$ Earth Change Observation Laboratory, Department of Geosciences and Geography, University of Helsinki, Helsinki, Finland \\ ${ }^{5}$ Department of Geography and Environment, York Institute for Tropical Ecosystem (KITE), University of York, York, UK \\ Email: d.odeny@gmail.com, dodeny@museums.or.ke
}

How to cite this paper: Odeny, D., Karanja, F., Mwachala, G., Pellikka, P. and Marchant, R. (2019) Impact of Climate Change on Species Distribution and Carbon Storage of Agroforestry Trees on Isolated East African Mountains. American Journal of Climate Change, 8, 364-386.

https://doi.org/10.4236/ajcc.2019.83020

Received: June 21, 2019

Accepted: August 16, 2019

Published: August 19, 2019

Copyright (๑) 2019 by author(s) and Scientific Research Publishing Inc. This work is licensed under the Creative Commons Attribution International License (CC BY 4.0).

http://creativecommons.org/licenses/by/4.0/

(c) $\underset{\mathrm{EY}}{\mathrm{C}}$ Open Access

\begin{abstract}
Changes in climate will affect conditions for species growth and distribution, particularly along elevation gradients, where environmental conditions change abruptly. Agroforestry tree (AGT) species on the densely inhabited slopes of Mount Kilimanjaro and Taita Hills will change their elevation distribution, and associated carbon storage. This study assesses the potential impacts of climate change by modelling species distribution using maximum entropy. We focus on important agroforestry tree species (Albiziagummifera, Mangiferaindica and Perseaamericana) and projected climate variables under IPCC-AR5 RCP 4.5 and 8.5 for the mid-century (2055) and late century (2085). Results show differential response: downward migration for $M$. indica on the slopes of Mount Kilimanjaro is contrasted with Avocado that will shift upslope on the Taita Hills under RCP 8.5. Perseaamericana will lose suitable habitat on Kilimanjaro whereas $M$. indica will expand habitat suitability. Potential increase in suitable areas for agroforestry species in Taita Hills will occur except for Albizia and Mango which will potentially decrease in suitable areas under RCP 4.5 for period 2055. Shift in minimum elevation range will affect species suitable areas ultimately influencing AGC on the slopes of Mount Kilimanjaro and Taita Hills. The AGC for agroforestry species will decrease on the slopes of Mount Kilimanjaro but AGC for Mango will increase under RCP 8.5 for period 2055 and 2085. In Taita Hills, AGC will remain relatively stable for A. gummifera and P. americana under RCP 8.5 for period 2055 and 2085 but decrease in AGC will occur for $M$. indica under projected climate change.
\end{abstract}


Climate change will affect AGT species and the amount of carbon stored differently between the sites. Such insight can inform AGT species choice, and conservation and support development by improving carbon sequestration on sites and reliable food production.

\section{Keywords}

Agroforestry, Carbon Storage, Climate Change, Albizia, Avocado, Mango

\section{Introduction}

Atmospheric accumulation of anthropogenic greenhouse gases, in particular a doubling of $\mathrm{CO}_{2}$, is linked to the rise in global temperature estimated at an average of $1.5^{\circ} \mathrm{C}$ [1]. Increase in global temperature has caused shifting of species distribution, population structure and abundance towards the pole [2]. Species on montane ecosystems with steep climate gradient are at risk from global warming due to potential upward shift of species ranges and habitat fragmentation [2]. Climate change is envisaged to change potential species distribution area and survival in the 21st century; though at present, land use by human population remains the main driver of species extinction and habitat loss [3].

Climatic conditions have changed in the recent years in East Africa due to natural climate variability and land use change [4]. The temperatures in the region have risen by approximately $1.3^{\circ} \mathrm{C}$ since 1960 [5]; similarly, rainfall distribution and quantity have varied over space in the Horn of Africa [6]. Although an increase in average precipitation over the region is predicted [7], incidences of increased drought and floods have been recorded alongside seasonal variation of precipitation [7] [8]. Climate change projections indicate annual temperatures will increase by $1.8^{\circ} \mathrm{C}$ to $4.3^{\circ} \mathrm{C}$ by 2080 in East Africa with greatest warming occurring from June to August [7]. Projected climate change is likely to affect East Africa's socio-economic sectors, particularly those reliant on land. Where greater rainfall variability within and between seasons occurs, crop productivity will considerably be affected. For instance, maize and certain bean varieties may decline in yield [7]. Subsistence farming is most vulnerable to climate change due to lack of sufficient resources to adapt to climate change [9].

The agroforestry system is increasingly gaining importance in increasing food production, enhancement of crop productivity, soil enrichment and wider mitigation effects of climate change through enhanced carbon sequestration and other ecosystem services [9] [10] [11]. Agroforestry increases amount of carbon sequestered in the above and belowground compared to a monoculture field of crop plants or pasture [10] [12] [13]. Improvement of cropland management practices such as management of trees increases carbon sequestration [10] [14]. Agroforestry plays an important role in enhancement and maintenance of long-term soil productivity and sustainability by improving amount of organic matter and releasing and recycling of soil nutrients [10] [15]. Agroforestry sys- 
tems have high potential to conservation due to their structural complexity, high floristic diversity and close resemblance to forest ecosystems [16]. Biodiversity conservation by agroforestry is through provision of habitat for species and connectivity of scattered habitats; preservation of germplasm of sensitive species, and ecosystem services [10]. For instance, the shade coffee agroforestry system has high potential to enhance biodiversity compared to traditional agricultural practices [10] [17] [18].

Less effort is directed in understanding how species of agroforestry system would be affected by climate change despite the attributed importance on carbon sequestration and biodiversity conservation. Insight is required to establish extent to which species would be affected in order to plan for their future conservation and management [19]. Robust prediction models for impact of climate change on agroforestry systems are not available [20]; however prediction of habitat suitability can be made by models that employ species location [21] via species distribution modelling (SDM) which provides an alternative approach to projecting climate change impacts [20]. The potential species distribution areas are considered to possess conditions that are suitable for survival of the species and can be used to estimate species' realized distribution [22]. Thus, agricultural systems can be evaluated with methods typically used for studying organisms.

One challenge with exotic agroforestry trees is that they are they are often grown outside their normal environmental niche so the record of where these are found can be a challenge to fit a modelling framework. For instance, most of agroforestry trees consist of exotic species that are not sufficiently covered by most Natural History Museums/Botanical Garden herbarium collections. Thus, the number of sightings for the species (training examples); will often be small, a hundred or less [22]. When occurrence records for the species are distributed within a small geographic area, modeling affects accuracy of coinciding the species realized niche and fundamental niche [23]. Lastly, existing environmental data does not have suitable resolution that synchronizes with the local climate variables [20] [24]. Bioclimatic conditions often vary widely over short distances, especially in mountainous terrain, which is characterized by steep gradients often not reflected in the available datasets [19] [20]. In order to solve this challenge, a high-resolution bioclimatic variable (downscaled) can be used in order to capture local topographic characteristics that affects climate in the mountainous areas [24]. The issue of small sample size can be solved by using cross-validation which uses all the data for validation that makes better use of small data sets [23]. Accuracy for species fundamental niche along the elevation gradients can be improved by using data from a larger geographical extent and zooming along the slopes of the mountains [23].

The focus of this research was to predict the effect of climate change on agroforestry tree species distribution and carbon storage in montane areas (Mount Kilimanjaro and Taita Hills). Three agroforestry tree species selected were Albiziagummifera (Albizia), Mangiferaindica (mango) and Perseaamericana (avo- 
cado), which are dominant agroforestry tree species and contribute substantial amount of aboveground carbon on the slopes of Mount Kilimanjaro and Taita Hills [25]. Mango and avocado are exotic fruit tree species that are cultivated for their fruits and provide local income. Albizia is an indigenous tree species that is preserved on the fields for shading and improve farming conditions via nitrogen fixation. Avocado has various cultivars that are adapted to different climatic conditions. Depending on the cultivar, avocado grows in area with an average rainfall of $800 \mathrm{~mm}$ for five months, mean annual temperature of $12.5^{\circ} \mathrm{C}-25.5^{\circ} \mathrm{C}$ with a maximum of $32^{\circ} \mathrm{C}$ and a minimum of $2^{\circ} \mathrm{C}$ [26]. Mango grows in areas with the mean annual temperature between $24^{\circ} \mathrm{C}-30^{\circ} \mathrm{C}$ and an average annual rainfall between $890-1015 \mathrm{~mm}$. Albizia is common in lowland and upland rain-forest (usually at higher altitudes), riverine forest, and in open habitats near forests. It occasionally appears as a pioneer species in forests and in thickets. Modelling of the selected species used background layers of the baseline climate variables and projected climate change from the WorldClim2 data ensemble under IPCC-AR5 representative concentration pathways (RCP 4.5 and RCP 8.5) for mid-century 2055 (2041-2070) and the late century 2085 (2071-2100) [24]. The IPCC models and scenarios are used for projections of future climatology.

\section{Methodology}

\subsection{Study Area}

The study sites used in this research were the Taita Hills and Mount Kilimanjaro (Figure 1). The Taita Hills are located in Taita-Taveta County in southeastern Kenya having elevation range from $800 \mathrm{~m}$ to $2208 \mathrm{~m}$ at the top of Vuria. The research was carried out along a transect on the southeastern part of the hills from the lowlands in Mwatate (approx. $840 \mathrm{~m}$ ) to up to $1900 \mathrm{~m}$ above sea level close to Vuria. Both Taita Hills and Kilimanjaro experience two rainy seasons in a year. The long rains take place from March to May and the short rains from October to December. In Taita Hills over $1400 \mathrm{~m}$ a.s.l., the average rainfall is more than $1300 \mathrm{~mm}$ annually, while the surrounding plains have between 400 to 700 $\mathrm{mm}$ [27]. Due to the orographic rainfall pattern, the southeastern slopes of Taita Hills receive more precipitation than the northwestern slopes [28]. The Taita Hills experience an annual mean temperature that varies from $16^{\circ} \mathrm{C}$ to $18^{\circ} \mathrm{C}$; while the surrounding plains have an annual mean temperature of $25^{\circ} \mathrm{C}$. Two types of forests are found in the Taita Hills: native montane forests and exotic plantation forests of eucalyptus, pine and cypress. Mixed woodlands are present in the hills and on the slopes. The total area of native forest is about $6 \mathrm{~km}^{2}$ within three main patches of which $4 \mathrm{~km}^{2}$ is forest with closed and intact canopy of Mbololo, Chawia and Ngangao. The other native forests, such as Vuria, Fururu, KinyeshaMvua, have broken and non-contiguous canopy [29] [30]. As the soils are favourable and precipitation is sufficient on the study transect, most of the land is taken for small-scale agriculture with heterogenous crops and tree species. Agroforestry is very typical form of farming with mangos at lower elevations and 


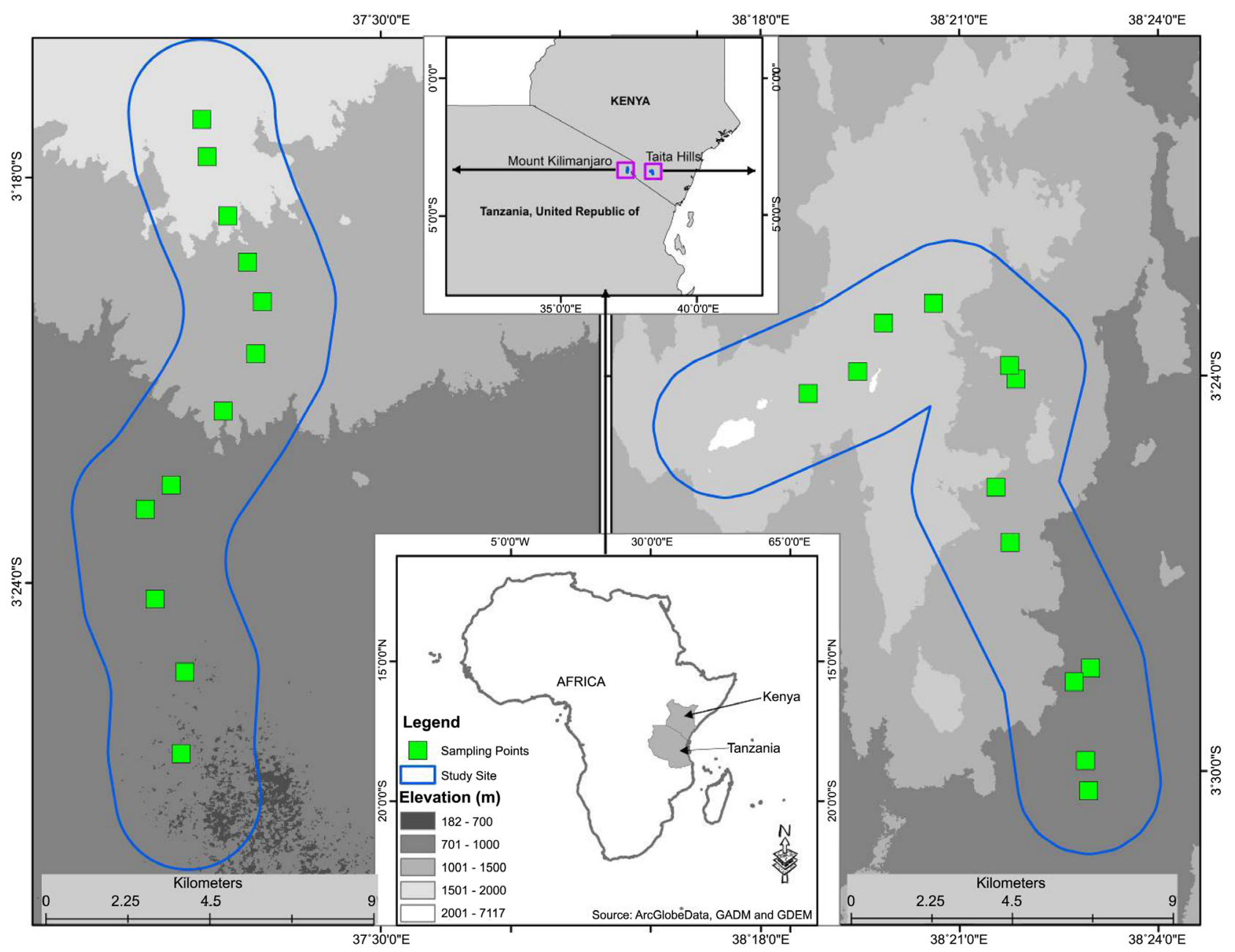

Figure 1. Research transects and study plots for the above-ground carbon storage on the Mt. Kilimanjaro on the left and TaitaHills on the right.

avocado in higher elevations. Exotic fruit trees are abundant on croplands, and the most typical agroforestry trees at an elevation range 1400 to $1800 \mathrm{~m}$ a.sl. are Acacia mearnsii, Cupressus lusitanica, Eucalyptus saligna, Grevillearobusta and Perseaamericana [31]. Most of the remaining vegetation and carbon storages are remaining on the slopes too steep for agriculture [32].

On Mt. Kilimanjaro the research was carried out along a transect on south-eastern slopes from $720 \mathrm{~m}$ to $2000 \mathrm{~m}$ over sea level. As noted in Taita Hills, rainfall here also varies along the research transect; in the highlands annual rainfall is between 1200 to $1800 \mathrm{~mm}$, while in lowlands around $900 \mathrm{~m}$ and midlands (900 $1200 \mathrm{~m}$ ) it ranges from 400 to $1200 \mathrm{~mm} \cdot \mathrm{yr}^{-1}$. The montane zone above $1800 \mathrm{~m}$ receives the highest rainfall in excess of $2000 \mathrm{~mm} \cdot \mathrm{yr}^{-1}$. Owing to the fertile soils and favourable climate, the area is densely settled and supports agriculture. The transect has three distinct agro-ecological zones: the highland zone with predominantly coffee and banana cultivation; midlands with predominantly maize and bean growing, and lowlands with dryland agriculture [33]. Below the Mt. Kilimanjaro National Park, a narrow forest strip was established 
in 1941 as a buffer zone to provide local people with wood and wood products [33].

\subsection{Species Distribution Modelling}

Distribution data for Avocado, Mango and Albizia spanning over landscapes in Kenya and Tanzania landscape (Figure 2) were acquired from the field data and online database specifically from the Global Biodiversity Information Facility (GBIF) and PROTO. The species; Avocado had 143 sample data points, Mango 99 data and Albizia had 159 sample data points. Environmental data consisted of the current (baseline) and future high-resolution ensemble climate projection layers for Africa acquired from WorldClim2. Climate variables included temperature and moisture related variables forming a total of 61 climate variables (Table 1). Future climate projection layers were based on the ensembled Representative Concentration Pathway of the IPCC-AR5 (RCP4.5 and RCP8.5) at $30 \mathrm{~s}$

Table 1. Climate variables that include temperature variables (tbio) and moisture variables (mbio) used as background environmental variable for modelling in maxent.

Temperature (tbio)

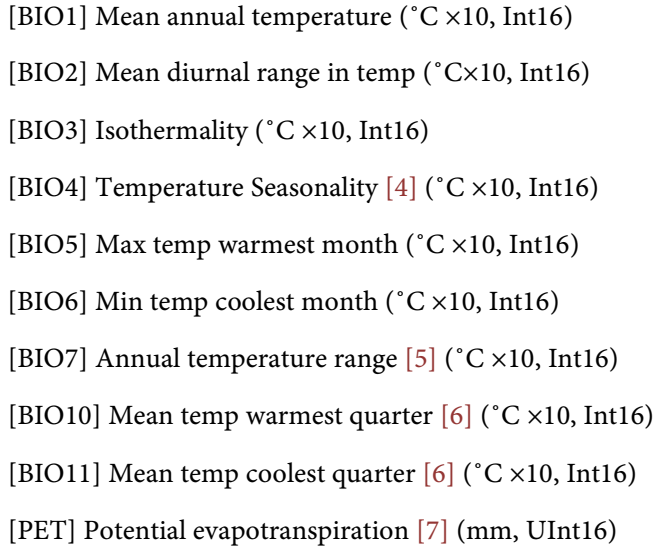

\section{Moisture (mbio)}

[BIO12] Mean annual rainfall [8] (mm, UInt16)

[BIO13] Rainfall wettest month (mm, UInt16)

[BIO14] Rainfall driest month (mm, UInt16)

[BIO15] Rainfall seasonality [4] (mm, UInt16)

[BIO16] Rainfall wettest quarter [6] (mm, UInt16)

[BIO17] Rainfall driest quarter [6] (mm, UInt16)

[MI] Annual moisture index [9] (×100, UInt16)

[MIMQ] Moisture index moist quarter [6] (×100, UInt16)

[MIAQ] Moisture index arid quarter [6] (×100, UInt16)

[DM] Number of dry months [10] (months, Byte)

[LLDS] Length of longest dry season [11] (months, Byte) 


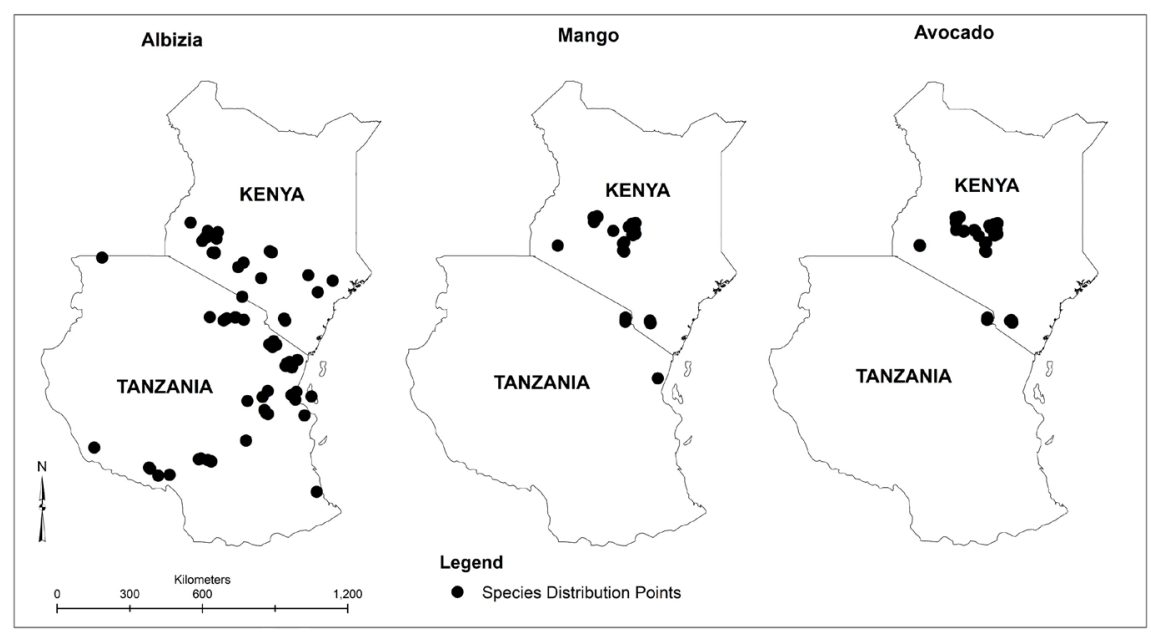

Figure 2. Distribution points of Albizia, Mango and Avocado trees in the landscape of Kenya and Tanzania.

resolution were used for prediction in the mid-century 2055 (mean over 2041-2070) and late-century 2085 (mean over 2071-2100).

Maximum entropy technique was used for modelling the distribution of Avocado, Mango and Albizia. This is because the technique has advantages over other techniques, namely: it uses present-only data with the environmental variable in the background; it uses both continuous and categorical data, and lastly; it can incorporate interactions between different variables [23].

Maxent was set to run under customized settings: random test point (25), Replicates (7), Replicate type (subsample), Replicated run type (crossvalidate), Maximum iteration (5000). Cross-validation has an advantage of using all data for validation, thus making better use of small data sets [23]. Other parameters were set at maxent default values. Fewer numbers of parameters were used for calibration since tuning large numbers of parameters for modelling often poses several challenges for instance, it may be prohibitive and time consuming to tune the method on each species separately. Besides, model accuracy is affected by several settings that determine the type and complexity of dependencies on the environment that maxent tries to fit [23]. Relative influence of the climate variables was assessed for each species in each climate models (baseline, RCPs and periods). This is performed by examining the contribution of each predictor to the final regularized training gain when all variables of the particular model were included in the Maxent run [34]. Maxent model performance was measured by the test omission rate which is considered good when the omission rate is close to the predicted omission. The area under the ROC curve (AUC), was used for measuring the performance of the maxent model.

\subsection{Species Above-Ground Carbon Calculation}

Biometric data for avocado, mango and Albizia were extracted from plot carbon data that were collected from the research transects. The plot carbon data were generated using a standard size plot of 1 ha [35] within which heights and diameter 
at breast height $(\mathrm{dbh}) \geq 10 \mathrm{~cm}$ of woody trees were sampled. A number of 12 Plots were established randomly within $20 \mathrm{~km}$ long transects in Taita Hills and Kilimanjaro in 2012 (Figure 1) [25]. The initial step of estimating the aboveground carbon is determining the aboveground biomass using the tree parameters (DBH \& height) measured on a plot and the wood density for each species $\left(\mathrm{g} / \mathrm{cm}^{3}\right)$. We retrieved the wood densities for each species, genus or family from the Global Wood Density Database [36] [37]. An allometric model developed by Chave et al., (2014) [38] was used for estimating the above-ground biomass (AGB) (Equation (1)).

$$
\mathrm{AGB}=0.0673 \times\left(\rho \times D^{2} H\right)^{0.976}
$$

where $\rho$ is the Wood Specific Gravity, $D$ is the dbh, and $H$ is the height of the tree. After deriving the AGB for each tree, data was aggregated to plot level from which $50 \%$ of AGB was assumed to be carbon sequestration in a plot [25] [38] [39].

\subsection{Prediction of Suitable Area and Carbon Storage}

Selection of suitable areas for Albizia, Mango and Avocado on the inhabited slopes of Mount Kilimanjaro and Taita Hills was performed on the probability distribution layers at probability $\geq 0.6$. The probability value of $\geq 0.6$ was selected as a threshold value based on the predicted baseline probability value of first occurrence point for Albizia on the slope of Mount Kilimanjaro. Once suitable areas for the species are derived with a threshold 0.6 probability distribution, potential shift of minimum elevation range for the species were assessed within transect buffer of 16,970 ha along the elevation. The elevation at the minimum suitable elevation range of a species suitable contiguous or fragmented polygon areas of the species were used to determine the shift of species distribution along the elevation. Shift in minimum suitable elevations range of the species was derived from the difference in predicted minimum suitable elevation range of projected climate change, IPCC-AR5 (RCP 4.5 and RCP 8.5) in the mid-century 2055 and late-century 2085, from the baseline prediction. While, change in area of distribution was indicated by percentage of increase or decrease in area of prediction of projected climate change, IPCC-AR5 (RCP 4.5 and RCP 8.5) in the mid-century 2055 and late-century 2085, and the baseline prediction.

The above-ground carbon (AGC) was predicted on assumption that the average species plot AGC on the slopes of Mount Kilimanjaro and Taita Hills will not vary under climate change. However, the total species carbon storage will only be affected by changes in suitable areas induced by the future climate change on the slopes of mountains. Thus, if baseline climate does not change then the total species AGC would remain the same in future on the slopes of the two mountains. An increase in suitable area would result into an increase in the total amount of species AGC in the area, and the converse is true. From 12 plots sampled, less number of plots would occur within the decreased suitable areas along the slopes of the mountains. Following this, species AGC were analyzed 
from suitable areas derived from the baseline climate conditions, RCP 4.5 and RCP 8.5 for periods 2040-70 and 2070-2100. Species plot AGC occurring within the suitable areas were used to generate the average species plot AGC (Equation (2)). The total amount of species AGC depends on the average species plot AGC and the total area predicted as suitable on the slope of the mountains. Thus, total amount of AGC is normalized by the total area of the transect buffer to derive predicted mean species AGC on the slopes of Mount Kilimanjaro and Taita Hills (Equation (3)).

$$
\begin{gathered}
\text { Average Species AGC }=\frac{\text { Total Species Plot AGC in Predicted Area }}{\text { Total Number of Plots in Transect }} \\
\text { Predicted Mean Species AGC }=\frac{\text { Average Species AGC } * \text { Predicted Area }}{\text { Total Area of Transect Buffer }}
\end{gathered}
$$

\subsection{Statistical Analysis}

The area under the ROC curve (AUC), was used for measuring the performance of the maxent model. The AUC is the probability that a randomly chosen presence site will be ranked above a randomly chosen absence site [23]. A random ranking has an average AUC of 0.5 , and a perfect ranking achieves the best possible AUC of 1.0; models with values above 0.75 were considered potentially useful [40]. Suitable areas and AGC for a species were compared between projected baseline species distribution and future projected periods using $\mathrm{Chi}^{2}$ test. Tables and map models were used for presentation of analysis of suitable areas, elevation shift of species and carbon storage for the species on the slopes of the mountains.

\section{Results}

\subsection{Species Distribution Modelling}

The prediction model for Albizia, Mango and Avocado under the projected climate change for baseline conditions, and RCP 4.5 and RCP 8.5 for periods of 2041-2070 and 2085 has the omission rate closer to the predicted omission; however, the prediction models show variations on the omission rate. The Maxent model performed well in predicting the distribution of the agroforestry tree species in the baseline prediction, RCP 4.5 and 8.5 projections for the periods 2041-2070 and 2000-2085. This is indicated by the Receiver Operating Characteristics (ROC) curve for the model that has very high average test Area Under Curve (AUC). Under baseline projection, Albizia has AUC 0.94, Mango 0.98, and Avocado 0.99. ROC AUC for the species under RCP 4.5 and 8.5 for the period 2041-2070 and 2085 for Albiziais 0.93, and Avocado is 0.99. The model for Mango under RCP 4.5 for the period 2041-70 has ROC AUC of 0.97. RCP 4.5 projection for period of 2085, RCP 8.5 for period 2055 and 2085 has ROC AUC of 0.98 .

The performance of maxent models was contributed by various climate variables as indicated by Jackknife test of regularized training gain and test gain. 
The maximum temperature for September increased the gain highly when used in isolation on Albizia under: RCP 4.5 for period 2055 and 2085, respectively and; RCP 8.5 for period 2085. However, the mean temperature of warmest quarter (Bio 10) increased the gain highly when used in isolation on Albizia under RCP 8.5 for period 2055. Conversely, the monthly precipitation for December decreased gain when it was omitted from modelling Albizia for baseline climate and RCP 4.5 for 2055. In modelling the distribution of Mango under baseline, and RCP 4.5 for periods 2055 and 2085, the November precipitation increased gain highly when it is used in isolation. The mean temperature warmest quarter increase gain highly when used in isolation on Mango under RCP 8.5 for period 2055. Climate variables that decreased gain when omitted from modelling Mango were the: February precipitation in baseline climate model, RCP 4.5 model for period 2055, and; mean temperature of warmest quarter for period 2085. In modelling Avocado for periods 2055 and 2085 under RCP 4.5, January temperature increased gain highly when used in isolation. The mean temperature of warmest quarter (Bio10) increased gain highly when it is used in isolation under RCP 8.5 for period 2055. Variables that decreased gain the most when omitted in modelling Avocado were: the monthly precipitation for February and May under baseline climate model; monthly precipitation for February under RCP 4.5 for period 2055, and; the mean temperature of warmest quarter (Bio10) under RCP 8.5 for period 2085 .

The model predicted the species well in areas data points occur including areas away from data points (inside white circles) as the potential distribution areas (Figure 3 ). The predicted distribution by climate models shows the distribution of most of the species occurs in Kenya mostly around the highlands. Albizia has a wider distribution area in Kenya while in Tanzania, its distribution occur around Mount Kilimanjaro and the Arc Mountain areas. The distribution of Avocado and Mango is apparently conspicuous around Kenya highlands than in Tanzania.

\subsection{Species Elevation Shift}

The three species have relatively different lower suitable elevation limits under current climatic conditions; Albizia has the lowest lower suitable elevation range in Kilimanjaro while in Taita Hills, Mango has lowest lower suitable elevation range than Albizia and Avocado (Table 2). The lower predicted suitable baseline elevation range of the species are significantly different across the sites $\left(\mathrm{Chi}^{2}\right.$ : DF $=2, \mathrm{p}=0.000)$ : the lowest predicted suitable baseline elevation range for Mango and Avocado in Kilimanjaro is $290 \mathrm{~m}$ and $372 \mathrm{~m}$ higher than the lower elevation of counterparts in Taita Hills. Albizia has the lowest predicted suitable baseline elevation range across the two sites. A potential shift in the minimum suitable elevation range for the three agroforestry tree species will occur on the slopes of Mount Kilimanjaro and Taita Hills in response to the projected climate change. Climate change under projection of RCP 4.5 will potentially cause an upward 


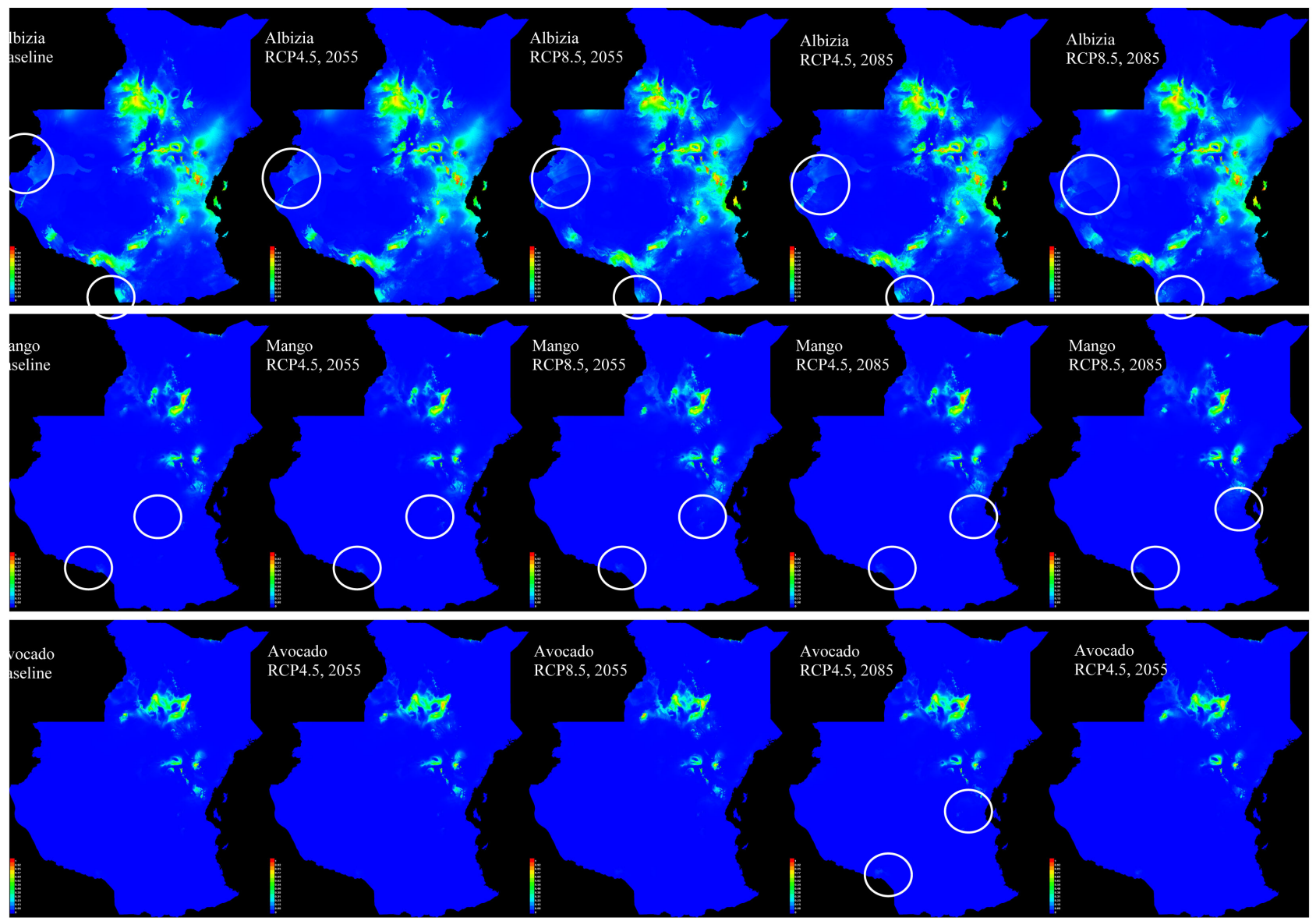

Figure 3. The images show the point-wise mean of the 7 output grids of projected climate (baseline, RCP 4.5 and 8.5 for 2055 and 2085) for A. gummifera, M. indica, and P. americana. The red colour areas indicate high probability occurrence of the species while the blue indicate the low probability distribution areas for the species

Table 2. Species shift along elevation $4 \mathrm{~km}$ width transects (Kilimanjaro transect buffer area 16,213 ha, 10 plots; Taita Hills transect buffer area 16,970 ha, 12 plots). The rate of shift with -ve sign means downshift while +ve means upshift along the elevation.

\begin{tabular}{|c|c|c|c|c|c|c|c|c|}
\hline Site & $\begin{array}{l}\text { Climate } \\
\text { Projection }\end{array}$ & Species & $\begin{array}{c}\text { Mean Species AGC } \\
\text { in study area ( } \mathrm{Mg} \\
\mathrm{C} / \mathrm{ha} .)\end{array}$ & $\begin{array}{l}\text { plots in } \\
\text { Predicted } \\
\text { Area }\end{array}$ & $\begin{array}{l}\text { Suitable } \\
\text { Predicted } \\
\text { Area (ha.) }\end{array}$ & $\begin{array}{l}\text { Predicted } \\
\text { mean AGC } \\
(\mathrm{Mg} \mathrm{C} / \mathrm{ha} .)\end{array}$ & $\begin{array}{c}\text { Minimum } \\
\text { elevation }(\mathrm{m})\end{array}$ & $\begin{array}{l}\text { Rate of shift in } \\
\text { elevation }(m)\end{array}$ \\
\hline \multirow{11}{*}{ Kilimanjaro } & & Albizia & 9.25 & 6 & 6315 & 3.60 & 982 & \\
\hline & Baseline & Mango & 1.84 & 5 & 4523 & 0.51 & 1067 & \\
\hline & \multirow{4}{*}{$\begin{array}{c}\mathrm{RCP} 4.5,2055 \\
\mathrm{~m}\end{array}$} & Avocado & 3.71 & 4 & 5803 & 1.33 & 1196 & \\
\hline & & Albizia & 6.67 & 5 & 5206 & 2.14 & 1167 & 3.4 \\
\hline & & Mango & 0.06 & 5 & 4438 & 0.02 & 792 & -5 \\
\hline & & Avocado & 3.37 & 4 & 3755 & 1.08 & 1092 & -1.9 \\
\hline & \multirow{3}{*}{ RCP 8.5, 2055} & Albizia & 7.08 & 6 & 5974 & 2.61 & 1047 & 1.18 \\
\hline & & Mango & 1.80 & 4 & 5376 & 0.66 & 803 & -4.8 \\
\hline & & Avocado & 3.00 & 2 & 2304 & 1.11 & 1459 & 4.78 \\
\hline & \multirow{2}{*}{ RCP 4.5, 2085} & Albizia & 9.66 & 7 & 6571 & 3.91 & 1009 & 0.32 \\
\hline & & Mango & 0.06 & 4 & 4267 & 0.02 & 811 & -3.01 \\
\hline
\end{tabular}




\begin{tabular}{|c|c|c|c|c|c|c|c|c|}
\hline \multicolumn{9}{|c|}{ Continued } \\
\hline & & Avocado & 1.60 & 2 & 2987 & 0.65 & 1429 & 2.74 \\
\hline & \multirow{3}{*}{ RCP 8.5, 2085} & Albizia & 9.25 & 6 & 5974 & 3.41 & 1066 & 0.99 \\
\hline & & Mango & 3.63 & 7 & 9558 & 1.34 & 757 & -3.65 \\
\hline & & Avocado & 3.71 & 4 & 5120 & 1.37 & 1146 & -0.59 \\
\hline & \multirow{3}{*}{ Baseline } & Albizia & 0.03 & 3 & 13,048 & 0.02 & 923 & \\
\hline & & Mango & 3.24 & 6 & 11,427 & 2.18 & 777 & \\
\hline & & Avocado & 1.13 & 9 & 10,660 & 0.71 & 824 & \\
\hline & \multirow{3}{*}{ RCP 4.5, 2055} & Albizia & 0.03 & 3 & 12,707 & 0.02 & 923 & 0 \\
\hline & & Mango & 2.67 & 3 & 10,745 & 1.69 & 777 & 0 \\
\hline & & Avocado & 1.08 & 8 & 11,683 & 0.81 & 777 & -0.86 \\
\hline & & Albizia & 0.03 & 3 & 13,644 & 0.02 & 906 & -0.31 \\
\hline \multirow[t]{8}{*}{ Taita Hills } & RCP 8.5, 2055 & Mango & 2.67 & 3 & 12,536 & 1.97 & 777 & 0 \\
\hline & & Avocado & 1.08 & 8 & 11,001 & 0.70 & 940 & 2.11 \\
\hline & & Albizia & 0.03 & 3 & 13,559 & 0.02 & 910 & -0.15 \\
\hline & RCP 4.5, 2085 & Mango & 2.67 & 3 & 12,195 & 1.92 & 777 & 0 \\
\hline & & Avocado & 1.08 & 8 & 10,660 & 0.68 & 940 & 1.37 \\
\hline & & Albizia & 0.03 & 3 & 15,009 & 0.02 & 777 & -1.72 \\
\hline & RCP 8.5, 2085 & Mango & 2.67 & 3 & 13,559 & 2.13 & 777 & 0 \\
\hline & & Avocado & 1.08 & 9 & 11,001 & 0.70 & 924 & 1.18 \\
\hline
\end{tabular}

shift in Albizia distribution at a rate of $3.4 \mathrm{~m} /$ year for period 2000 to $2055 \mathrm{in} \mathrm{Ki-}$ limanjaro, and a rate of $2.74 \mathrm{~m}$ elevation per year for Avocado for the period 2000 to 2085 (Table 2). Downward shift in elevation is potentially observed for Mango at $5 \mathrm{~m} \cdot \mathrm{yr}^{-1}$ in 2055 and $3.01 \mathrm{~m} \cdot \mathrm{yr}^{-1}$ in 2085; while Avocado would shift down at $1.9 \mathrm{~m} \cdot \mathrm{yr}^{-1}$ in 2055 on the slopes of Mount Kilimanjaro. Projection under similar RCP until the year 2085 will only affect downward shift of Mango in Kilimanjaro (Table 2). Significance difference is observed on the elevation shifts between the period 2000-2055 and 2000-2085 under RCP $4.5\left(\mathrm{Ch}^{2}: \mathrm{DF}=2, \mathrm{p}=\right.$ 0.000); most species will shifts in elevation mostly in the period 2000-2055.

Climate change projected at RCP 8.5 will cause a potential upshift in predicted suitable areas for Albizia and Avocado in Kilimanjaro; the latter will experience great upshift at $4.78 \mathrm{~m} / \mathrm{yr}$ for the period 2000-2055 (Table 2). In Taita Hills, the distribution of Avocado will experience considerable upshift (2.11 m/year) among other species. Downward shift at a rate of $4.8 \mathrm{~m} / \mathrm{yr}$ will be experienced by Mango; while similar shift is observed with Albizia in Taita Hills but very negligible (Table 2). Projection of RCP 8.5 to the period 2000-2085 see Mango mostly affected by downshift at $3.65 \mathrm{~m} / \mathrm{yr}$; while, Albizia will similarly affected by downshift at $1.72 \mathrm{~m} / \mathrm{yr}$. The effect of RCP 8.5 on projection periods has significantly difference on species elevation shift between the periods 2055 and 2085 on the slopes of Mount Kilimanjaro $\left(\mathrm{Chi}^{2}: \mathrm{DF}=2, \mathrm{p}=0.023\right)$ and Taita 
Hills $\left(\mathrm{Chi}^{2}: \mathrm{DF}=2, \mathrm{p}=0.000\right)$. However, no significant difference was observed on predicted elevation shift between RCP 4.5 and 8.5 in each site for the projected periods.

\subsection{Change in Suitable Areas and Above-Ground Carbon Storage}

An estimated area of $77 \%$ of the transect area is potentially suitable for Albizia followed by Avocado (69\%) and Mango (67\%) under the baseline prediction in Taita Hills. In Kilimanjaro, species that had highest potential suitable area along the slope was Albizia with 39\% of the area, followed by Mango (36\%) and Avocado (28\%). Under the climate change projection based on the RCP 4.5 (2055) in Taita Hills, Albizia has about $75 \%$ of the transect area suitable for distribution; while the least, Avocado has 58\%. In Kilimanjaro area, Albizia has $32 \%$ of the transect area suitable for distribution with the least being Avocado having 15\% potentially suitable. RCP 8.5, 2055 Climate Projection estimated large area of $80 \%$ in Taita Hills to be potentially suitable for Albizia, Mango (74\%) and Avocado (65\%). An estimated $37 \%$ of the transect area in Kilimanjaro is potentially suitable for Albizia, 33\% for Mango and 14\% of the area potentially suitable for Avocado. An estimated $80 \%$ of the transect area in Taita Hills is predicted under the RCP 4.5, 2085 Climate Projection as potentially suitable for Albizia, Mango (72\%), and Avocado (63\%), while, in Kilimanjaro, largest potential area of $41 \%$ is suitable for the distribution of Albizia followed by Mango (26\%) and Avocado (18\%). RCP 8.5, 2085 Climate Projection predicts $88 \%$ of the transect area in Taita Hills as potentially suitable for the distribution of Albizia, Mango (80\%) and Avocado (65\%). In Kilimanjaro slope, 37\% of the transect area is predicted potentially suitable for Albizia, Mango apparently has the highest area in the transect (59\%) predicted potential for distribution with Avocado having low area of $32 \%$ predicted for potential distribution.

Comparison of suitable areas between Kilimanjaro and Taita Hills predicted under the baseline climate condition for Albizia, Mango and Avocado shows significant difference $(\mathrm{F}=153.17, \mathrm{p}=0.01)$. While, no significant difference was observed among the three species on suitable areas within site. Under the RCP 4.5, 2055 Climate Projection comparison of the suitable areas for the three species between Kilimanjaro and Taita Hills was significantly different $(\mathrm{F}=303.76$, $\mathrm{p}=0.00$ ); while no significant difference was observed among the three species on suitable areas in each sites. The projection of climate change based on the RCP 8.5, 2055 show suitable areas for each species between Kilimanjaro and Taita Hills differed significantly $(F=216.96, p=0.00)$. While no significant difference was observed among the suitable areas for the three species in each sites. Suitable areas for Albizia, Mango and Avocado in Kilimanjaro and Taita Hills significantly differed in size $(\mathrm{F}=393.02, \mathrm{p}=0.00)$ based on the projection of climate change based on the RCP 4.5, 2085. Also, significant difference $(\mathrm{F}=$ $28.12, \mathrm{p}=0.03$ ) was observed among the three species on suitable areas in each sites. Based on RCP 8.5, 2085, potentially suitable areas for Albizia, Mango and Avocado in Kilimanjaro and Taita Hills do not differ significantly in size, and; 
no significant difference was observed among the species in each site.

Change of predicted suitable areas analyzed against predicted baseline area and AGC shows decrease in areas for most of the species on the slopes of Mount Kilimanjaro for the RCPs and periods of climate change projection. The slopes of Taita Hills will experience increase of predicted areas for the agroforestry tree species (Figure 4) but AGC will apparently decrease in size (kg/ha./yr) except for Avocado that will increase in Taita Hills. Avocado will decrease in suitable areas more than other species in Kilimanjaro under RCP 4.5 for periods 2055, 2085 and RCP 8.5 in 2055 (Figure 4). AGC for Avocado will as well decrease in size in the same RCP and periods. However, much decrease in AGC will occur in 2055 and 2085 under RCP 4.5 for Albizia on the slopes of Mount Kilimanjaro. Considerable suitable areas will increase for the species under RCP 4.5 and 8.5

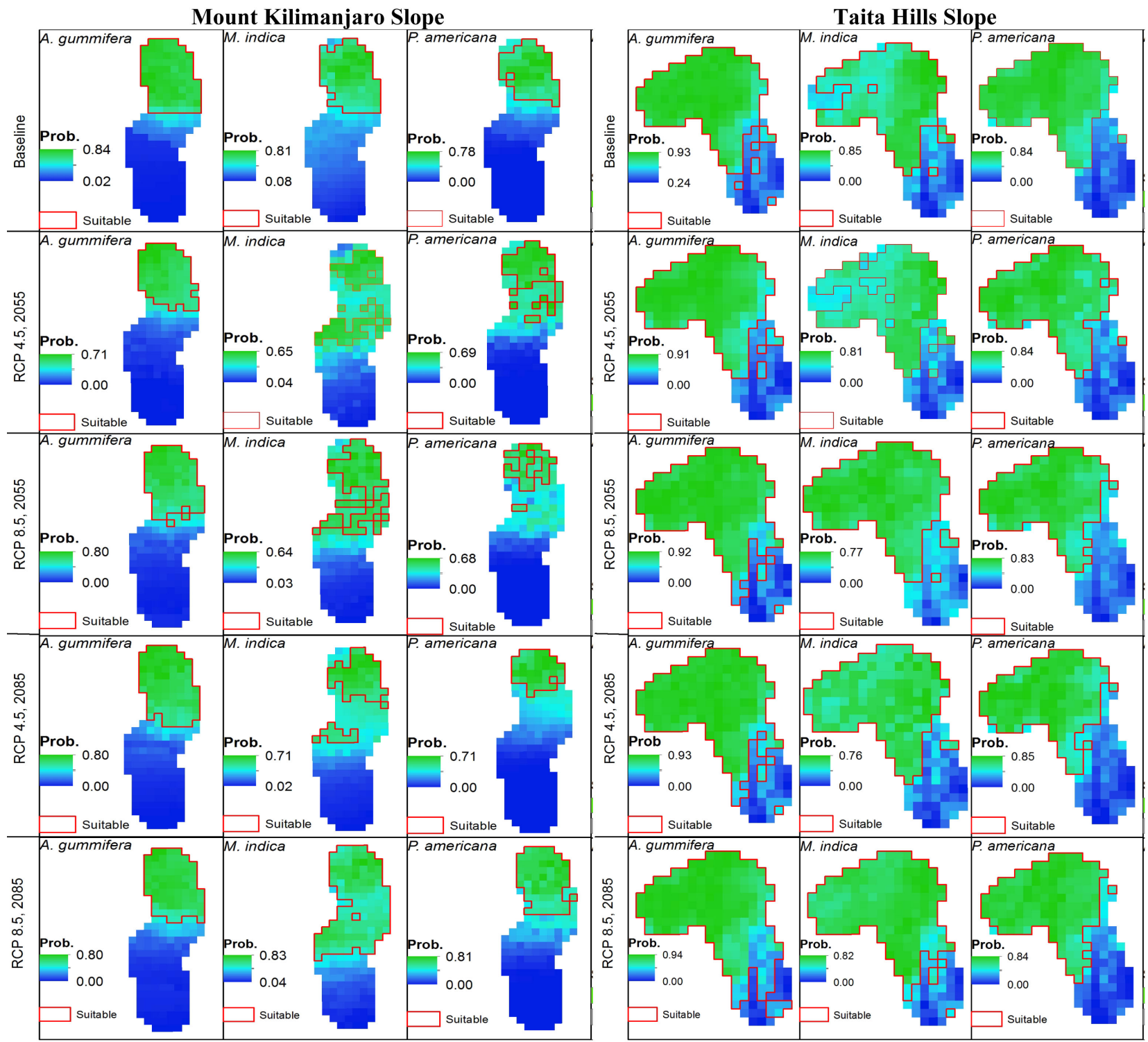

Figure 4. Changes in suitable area for Albizia, Mango and Avocado on the slope of Mount Kilimanjaro and the Taita Hills under RCP 4.5 and 8.5 for the average period of 2055 and 2085. 
for projected periods 2055 and 2085 (Figure 4). This is with exception for Albizia and Mango that will have percentage decrease in area under RCP 4.5 in period 2055, and; Avocado in 2085 where great decrease in area will be experienced (Figure 4). Despite some increase in suitable areas on the slopes of Taita Hills, Mango and Avocado will increase in AGC per hectare. The predicted AGC differ significantly in the distribution on the slope of Mount Kilimanjaro among species within baseline projection, 2055 and 2085 periods under RCP 4.5 (ANOVA, $\mathrm{F}=21.59, \mathrm{p}=0.0072$ ) and RCP (ANOVA, $\mathrm{F}=40.67, \mathrm{p}=0.0022$ ). Similar distribution pattern will be observed in Taita Hills where the variation in distribution of predicted AGC among species in Taita Hills will be significantly different within periods (RCP 4.5: ANOVA, $\mathrm{F}=109.47, \mathrm{p}=0.00032$, and $\mathrm{RCP}$ 8.5: ANOVA, $F=864.61, p=0.000005)$. Projected climate change under RCP 8.5 will cause more variation in the distribution of AGC among agroforestry species on the inhabited slopes of Taita Hills than the implication of RCP 4.5. In overall, variation of predicted AGC among the species will be less on the slope of Mount Kilimanjaro than on the slopes of Taita Hills. While, no significant difference will be observed among periods for each species under RCP 4.5 and 8.5 in Mount Kilimanjaro and Taita Hills.

\section{Discussion}

Agroforestry system supplement carbon sequestration in the above and below ground sectors [41]. The system; however has less carbon than indigenous and plantation forest but they certainly have more carbon than in agricultural cropped land [25] [42]. Besides, the system provide an array of products including fruit food, timber for building, fuelwood, and ecosystem services [43]. The broader cropland on the slopes of Mount Kilimanjaro and Taita Hills are preserved with indigenous and planted agroforestry trees that contribute to long-term local carbon storage [13] [25]. The selected agroforestry trees in this study play an important role in carbon sequestration on the slopes of Mount Kilimanjaro and Taita Hills. Both Avocado and Mango provide fruit food and socio-economic income to the local people; while Albizia is used for shading of coffee on the slopes of Mount Kilimanjaro. In both sites, Mango is grown in the lower elevation but farming of Avocado overlaps with Mango at the mid elevation in the inhabited areas and transcend upwards to the edge of the forests. The distribution of the trees along the slopes is influenced by the variation of climatic variables and inherent tolerance range of the species to the physical variables. The projected climate change which is expected to cause changes in temperature and precipitation will affect the ecological requirements of the agroforestry tree species in the region. This study demonstrates the response of these species to the projected climate change in terms of species elevation shifts, change on size of suitable area and change in carbon storage.

The global mean surface temperature is projected to increase between $1.5^{\circ} \mathrm{C}$ and $5.8^{\circ} \mathrm{C}$ by 2100 ; where Africa will be much warmer than the global annual 
mean warming. The mean annual temperature of the Sub-Saharan Africa is projected to range between $26.4^{\circ} \mathrm{C}-27.6^{\circ} \mathrm{C}$ by late century under RCP 4.5 or $27.9^{\circ} \mathrm{C}$ - $29.8^{\circ} \mathrm{C}$ under RCP 8.5 [24]. The projected climate at a local scale of the slopes of Mount Kilimanjaro and Taita Hills shows a relative increase in the mean annual temperature and precipitation with the highest occurring under RCP 8.5 in 2085 (Table 3). Even though precipitation is expected to increase in East Africa in the late century from the current $5 \%$ to about $20 \%$ [24], variation will occur across the landscape. These variations will affect how species will respond to climate change at a local scale. Based on current observations the baseline minimum elevation range for each species are different between the slopes of Mount Kilimanjaro and Taita Hills; the minimum elevation range are higher in Kilimanjaro for each species but lower in Taita Hills. This indicates that the baseline environmental conditions are already different between the sites creating difference on the observed suitable minimum baseline elevations. Despite increased warmer annual conditions causing upshift in species, Platts et al., (2013) [44] predicted that some species will shift downslope and this will be driven by changes in seasonality and water availability.

This study highlights a relative increase in temperatures on the slopes of Mount Kilimanjaro and Taita Hills. However, there is difference in precipitation between the two sites where Taita Hills will experience relatively higher amount of precipitation than in Kilimanjaro (Table 3 ). This means there will be more water available in Taita Hills than on the slopes of Kilimanjaro. On the other hand, a potential increase of the mean annual temperature on the slope of Mount Kilimanjaro will be accompanied by a relatively stable precipitation except in 2085 under RCP 8.5 when precipitation will be relatively high (Table 3 ). Plants that will be in areas with an increased warming but relatively stable precipitation will be affected adversely on growth and restricted distribution. Water availability is the primary determinant of vegetation distribution across the landscape due to its importance on the growth of plant species [45]. The increased

Table 3. Projected climate variables on the transect buffers on the inhabited slopes of Mount Kilimanjaro and Taita Hills under RCPs 4.5 and 8.5 for the periods 2055 and 2085.

\begin{tabular}{|c|c|c|c|c|c|c|}
\hline \multirow{2}{*}{ Site } & \multirow{2}{*}{ Climate Variables } & \multicolumn{5}{|c|}{ Climate Projections } \\
\hline & & Baseline & RCP4.5, 2055 & RCP4.5, 2085 & RCP8.5, 2055 & RCP8.5, 2085 \\
\hline \multirow{4}{*}{ Kilimanjaro } & Mean Annual Temperature & 20.4 & 22.2 & 22.6 & 23.0 & 24.4 \\
\hline & Temperature Range & $16.1-23.8$ & $18.0-25.8$ & $18.4-26.2$ & $18.7-26.4$ & $20.2-28.0$ \\
\hline & Mean Annual Precipitation & 1138 & 1178 & 1198 & 1151 & 1287 \\
\hline & Precipitation Range & $619-1859$ & $655-1857$ & $672-1894$ & $653-1819$ & $727-2009$ \\
\hline \multirow{3}{*}{ Taita } & Mean Annual Temperature & 20.3 & 22.0 & 22.4 & 22.7 & 24.0 \\
\hline & Temperature Range & $16.7-24.0$ & $18.5-25.8$ & $18.8-26.2$ & $19.1-26.4$ & $20.5-27.9$ \\
\hline & Mean Annual Precipitation & 1130 & 1212 & 1230 & 1231 & 1313 \\
\hline
\end{tabular}


warming in Taita Hills accompanied by increased precipitation will provide water for ecological growth and distribution on the landscape. Due to this phenomenon, most of the agroforestry tree species are observed increasing in suitable areas of distribution in downslope and upslope on the slope of Taita Hills. Based on observation on this study, projected increase in temperature without compensation of precipitation will cause potential upshift of the selected agroforestry tree species. The response of the selected agroforestry species is associated with the climate gain and loss on the slope of mountains. Upshift of species is associated by the gains of temperature and loss of precipitation related variables; which is mostly observed with Albizia and Avocado on the slopes of Mount Kilimanjaro (Table 4). In Taita Hills, upshift occurs only with Avocado where the temperature related variables gain mostly. Downshift of the agroforestry species is experienced where some precipitation variables will gain mostly while others loss in all sites (Table 4); these include Avocado and Mango in Kilimanjaro and Avocado and Albizia in Taita Hills (Table 4).

The spatial patterns of woody covers and other vegetation are strongly controlled by the frequency, extreme events of precipitation and the amount of rainfall [45]. In this study, carbon storage of the selected agroforestry trees is also observed responding to the gains and loss of climate variables. Carbon storage

Table 4. Climate gain and loss under RCPs 4.5 and 8.5 for periods of 2055 and 2085 and indication of direction of shift for species along the inhabited slopes of Mount Kilimanjaro and Taita Hills. Downshift $(\downarrow)$ and upshift $(\uparrow)$ and No shift (-)

\begin{tabular}{|c|c|c|c|c|c|c|c|}
\hline \multirow{2}{*}{$\begin{array}{c}\text { Climate } \\
\text { Projection }\end{array}$} & \multirow[b]{2}{*}{ Species } & \multirow[b]{2}{*}{ Climate gained } & \multirow[b]{2}{*}{ Climate lost } & \multicolumn{2}{|c|}{ Kilimanjaro } & \multicolumn{2}{|c|}{ Taita Hills } \\
\hline & & & & $\begin{array}{l}\text { Species } \\
\text { shift }\end{array}$ & $\begin{array}{l}\text { AGC Mg C/ha } \\
\text { (change) }\end{array}$ & $\begin{array}{l}\text { Species } \\
\text { shift }\end{array}$ & $\begin{array}{c}\text { AGC Mg C/ha } \\
\text { (change) }\end{array}$ \\
\hline \multirow{2}{*}{ RCP 4.5, 2055} & Albizia & $\begin{array}{c}\text { September maximum } \\
\text { temperature }\end{array}$ & December precipitation & $\uparrow$ & $2.14(-1.46)$ & - & $0.02(0.00)$ \\
\hline & Avocado & $\begin{array}{l}\text { January minimum } \\
\text { temperature }\end{array}$ & February precipitation & $\downarrow$ & $1.08(-0.25)$ & $\downarrow$ & $0.81(+0.10)$ \\
\hline \multirow{3}{*}{ RCP 8.5, 2055} & Albizia & $\begin{array}{c}\text { Mean temp warmest } \\
\text { quarter }\end{array}$ & Mean temp warmest quarter & $\uparrow$ & $2.61(-0.99)$ & $\downarrow$ & $0.02(0.00)$ \\
\hline & Mango & $\begin{array}{c}\text { Mean temp warmest } \\
\text { quarter }\end{array}$ & Mean temp warmest quarter & $\downarrow$ & $0.66(+0.15)$ & - & $1.97(-0.21)$ \\
\hline & Avocado & $\begin{array}{c}\text { Mean temp warmest } \\
\text { quarter }\end{array}$ & Mean temp warmest quarter & $\uparrow$ & $1.11(-0.22)$ & $\uparrow$ & $0.7(-0.01)$ \\
\hline \multirow{3}{*}{ RCP 4.5, 2085} & Albizia & $\begin{array}{l}\text { September maximum } \\
\text { monthly temperature }\end{array}$ & December precipitation & $\uparrow$ & $3.91(+0.31)$ & $\downarrow$ & $0.02(0.00)$ \\
\hline & Mango & November precipitation & December precipitation & $\downarrow$ & $0.02(-0.49)$ & - & $1.92(-0.26)$ \\
\hline & Avocado & January temperature & January \& May precipitation & $\uparrow$ & $0.65(-0.68)$ & $\uparrow$ & $0.68(-0.03)$ \\
\hline \multirow{3}{*}{ RCP 8.5, 2085} & Albizia & $\begin{array}{l}\text { September maximum } \\
\text { monthly temperature }\end{array}$ & December precipitation & $\uparrow$ & $3.41(-0.19)$ & $\downarrow$ & $0.02(0.00)$ \\
\hline & Mango & November precipitation & February precipitation & $\downarrow$ & $1.34(+0.83)$ & - & $2.13(-0.05)$ \\
\hline & Avocado & February precipitation & January precipitation & $\downarrow$ & $1.37(+0.04)$ & $\uparrow$ & $0.7(-0.01)$ \\
\hline
\end{tabular}


of the selected agroforestry trees species is predicted to decrease where: 1) there will be gains of temperature and loss of precipitation variables, and 2) probably, where some important precipitation variables loss and less important variable to species growth gain. In these scenarios, reduction in species carbon storage will take place whether there is upshift or downshift, or no shift in species distribution. The projected increase in species carbon storage will occur due to gains in precipitation variables and the minimum temperatures. The projected upslope movement of Avocado is associated with the gains in temperature variable which probably causes reduced cold condition in higher elevation of the inhabited slopes. This creates optimal growth temperature condition in the upland but increases the minimum suitable elevation, reduces suitable areas in the lower elevations and causes species carbon storage to decrease. The response of species to climate is also observed by Platts et al., [44] that forest cover will increase in uplands due to increased temperature; however lower limits of cover is not explained. Some of the findings contradicts observation that phenomenal species shift induced by climate change is likely to affect adversely the area for species distribution, the conservation and agricultural crop in tropical montane areas [9]. Increase in temperatures with a relatively stable or increased precipitation in the lowland will cause downshift of Mango on the slopes of the mountains (Table 4) which increase the population and production of the species. A contrasting response of species to climate change is observed on Albizia between Kilimanjaro and Taita where the species will shift upwards and decrease in carbon storage in Kilimanjaro probably due to the gains in temperature variables in the upland. In contrast, Albizia will shifts downwards in the lowlands of Taita Hills with relatively stable carbon storage due to the gains in monthly maximum temperature in Taita Hills (Table 4).

The choice for agroforestry tree species for improvement of carbon storage on the slopes of Mount Kilimanjaro and Taita Hills will depend on the species response to the projected climate change scenario. Species that increases in carbon storage under the two scenario and periods would be a good candidate for farmers. While considering that upshift and downshift of species is inevitable; the main objective would be to choose species that no matter what, carbon storage will improve on the slopes of the mountains. The future potential priority species for increasing carbon storage on the slopes of Taita Hills in both uplands and lowland is Avocado which shows potential relative increase in suitable areas under RCP 4.5 in 2055. Climate change under scenario RCP 8.5 will provide the inhabited slopes of Mount Kilimanjaro with a potential increase in carbon storage for Mango in 2055 and 2085. Species that will increase in suitable areas where precipitation variables will gain but show no shift in elevation can improve carbon sequestration by additional land management techniques (Table 4). The selected agroforestry tree species for modelling restricted choice of species for carbon sequestration on the inhabited slopes of Mount Kilimanjaro and Taita Hills under different climate change scenario. Consideration of several species with varied contribution of carbon sequestration will provide a holistic 
strategy for managing carbon storage on the slopes. The success in modelling of the agroforestry tree species therefore provide information that potentially contribute to conservation and development of agroforestry resources for improvement of carbon sequestration. In addition, local farmers would be able to adjust and putting up appropriate measures for ensuring reliable food security and income from agroforestry trees.

The use of species occurrence data and climate model variables in this study potentially present uncertainty in interpretation of the results. Dataset acquired from observations and herbarium often shows strong geographic bias (sampling bias) due to some areas being visited more often than others because of their accessibility [46] [47]. The availability of presence distribution data for species poses challenge as most of herbaria in the region lack sufficient data for modelling [47]. Such challenges has however been overcome by use of cross-validation in maxentmodelling technique which uses few data points. Species occurrence data can be biasedly distributed on the landscape which can contribute to local biasness and over-smoothing affecting reliability of the model [46] [48]. We, however, rely on maxent ability in using jackknifing to achieve a robust new estimator, called jackknife kriging, which retains ordinary kriging simplicity and global unbiasedness while at the same time reducing local bias and over-smoothing tendency [48]. The climate model consist of potentially highly correlated variables; however, maxent can only select one of variables in a pair of highly correlated variables and still model performance is not affected [22] [34]. However, the selection of variables by maxent is associated with the risk of diminishing importance of other predictor in the pairs of variables [22] [34]. It is also important to note that there are confounding factors that may affect the distribution of agroforestry tree species on the slopes of Mount Kilimanjaro and Taita Hills. These factors include but not limited to soil, market forces and land use plan and management.

\section{Conclusion}

Climate change will cause an increase in the mean annual temperature across the landscape of Kilimanjaro and Taita Hills under RCP 4.5 and 8.5 by the period 2055 and 2085. The inhabited slopes of Taita Hills will, however, experience relatively higher precipitation but the slope of Kilimanjaro will be relatively stable in precipitation. These phenomenal changes in climate will cause some species to shift upslope, downslope or no directional shift along the slopes. Variations in gain and loss of particular climate variable at local scale will induce a unique difference in the response of agroforestry tree species. In particular, the upshift of species distribution is associated with the reduction in species carbon storage on the slopes of Mount Kilimanjaro and Taita Hills which apparently is explained by the gains in temperature variables. An exception is observed on Albizia in Kilimanjaro which shift upslope but increases in carbon storage. Downshift of species is mostly associated with the gain in precipitation; however spe- 
cies carbon storage would increase or reduce on the slopes of Mount Kilimanjaro, or no change in species carbon storage. Avocado will shift upwards under RCP 8.5 and 4.5 in 2055 and 2085, respectively. The upshift will cause reduction in area of distribution which will adversely affect species carbon storage in Kilimanjaro and Taita Hills. While under RCP 4.5, avocado will shift downslope in Kilimanjaro and Taita Hills by 2055 though species carbon will decrease in the former but increase in the latter. Response of species to other RCPs and period contrast between the two sites. Upshift of agroforestry species will cause decrease in carbon storage and affect adversely livelihood of local population that depend on the agroforestry resources on the slopes of the mountains.

\section{Acknowledgements}

The research was funded by Ministry for Foreign Affairs of Finland under CHIESA project (Climate change impacts on Ecosystem Services and Food Security in East Africa) and BIODEV project (Building biocarbon and rural development in West Africa). The Taita Research station of the University of Helsinki is acknowledged for logistical space and research support. The York Institute for Tropical Ecosystem (KITE) provided resources and support for staying at York city during data analysis. I'm grateful to the National Museums of Kenya and the University of Nairobi for their immense in-kind support during the fieldwork and development of the manuscript.

\section{Conflicts of Interest}

The authors declare no conflicts of interest regarding the publication of this paper.

\section{References}

[1] IPCC (2018) Framing and Context. In: Masson-Delmotte, V., Zhai, P., Pörtner, H.-O., Roberts, D., Skea, J., Shukla, P.R., Pirani, A., Moufouma-Okia, W., Péan, C., Pidcock, R., Connors, S., Matthews, J.B.R., Chen, Y., Zhou, X., Gomis, M.I., Lonnoy, E., Maycock, T., Tignor, M. and Waterfield, T., Eds., Global Warming of $1.5^{\circ} \mathrm{C}$. An IPCC Special Report on the Impacts of Global Warming of $1.5^{\circ} \mathrm{C}$ above Pre-Industrial Levels and Related Global Greenhouse Gas Emission Pathways, in the Context of Strengthening the Global Response to the Threat of Climate Change, Sustainable Development, and Efforts to Eradicate Poverty, in press.

[2] Scheingross, J. (2007) Predicting Species Distribution of Sierra Nevada Butterflies in Response to Climate Change. Sierra Nevada Butterfly Distribution Models.

[3] Dawson, T.P., Jackson, S.T., House, J.I., Prentice, I.C. and Mace, G.M. (2011) Beyond Predictions: Biodiversity Conservation in a Changing Climate. Science, 332, 53. https://doi.org/10.1126/science.1200303

[4] Maeda, E.J., Wiberg, D. and Pellikka, P.K.E. (2011) Estimating Reference Evapotranspiration Using Remote Sensing and Empirical Models in a Region with Limited Ground Data Availability in Kenya. Applied Geography, 31, 251-258. https://doi.org/10.1016/j.apgeog.2010.05.011

[5] Chidumayo, E., Okali, D., Kowero, G. and Larwanou, M. (2011) Climate Change and African Forest and Wildlife Resources. African Forest Forum, Nairobi. 
[6] Marchant, R. (2007) The Importance of the Indian Ocean for Climate Change in East Africa. Ship and Ocean News, 13, 282-284. (In Japanese)

[7] Hove, H., Echeverria, D. and Parry, J.E. (2011) Review of Current and Planned Adaptation Action: East Africa. International Institute for Sustainable Development, Winnipeg.

[8] Naess, L.O., Sullivan, M., Khinmaung, J., Crahay, P. and Otzelberger, A. (2010) Changing Climates Changing Lives: Adaptation Strategies of Pastoral and Agro-Pastoral Communities in Ethiopia and Mali. ACF International, IDS, Tearfund, IER, A-Z CONSULT, ODES.

[9] Verchot, L.V., Noordwijk, M.V., Kandji, S., Tomich, T., Ong, C., Albrecht, A., Mackensen, J., Bantilan, C., Anupama, K.V. and Palm, C. (2007) Climate Change: Linking Adaptation and Mitigation through Agroforestry. Mitigation and Adaptation Strategies for Global Change, 12, 901-918. https://doi.org/10.1007/s11027-007-9105-6

[10] Jose, S. (2009) Agroforestry for Ecosystem Services and Environmental Benefits: An Overview. Agroforestry Systems, 76, 1-10.

[11] Schroeder, P. (1994) Carbon Storage Benefits of Agroforestry Systems. Agroforestry Systems, 27, 89-97. https://doi.org/10.1007/BF00704837

[12] Kirby, K.R. and Potvin, C. (2007) Variation in Carbon Storage among tree Species: Implications for the Management of a Smallscale Carbon Sink Project. Forest Ecology and Management, 246, 208-221.https://doi.org/10.1016/j.foreco.2007.03.072

[13] Pellikka, P.K.E., Heikinheimo, V., Hietanen, J., Schäfer, E., Siljander, M. and Heiskanen, J. (2018) Impact of Land Cover Change on Aboveground Carbon Stocks in Afromontane Landscape in Kenya. Applied Geography, 94, 178-189. https://doi.org/10.1016/j.apgeog.2018.03.017

[14] IPCC (2000) Land Use, Land-Use Change, and Forestry. A Special Report of the IPCC. Cambridge University Press, Cambridge, 375.

[15] Young, A. (1997) Agroforestry for Soil Management. 2nd Edition, CABI Publishing, Wallingford, 320.

[16] Schroth, G., Fonseca, G.A.B., Harvey, C.A., Gascon, C., Vasconcelos, H.L. and Izac, A.M.N. (2004) Agroforestry and Biodiversity Conservation in Tropical Landscapes. Island Press, Washington DC.

[17] Hailu, B.T., Maeda, E.E., Pellikka, P.K.E. and Pfeifer, M. (2015) Identifying Potential Areas of Understorey Coffee in Ethiopia's Highlands Using Predictive Modelling. International Journal of Remote Sensing, 36, 2898-2919. https://doi.org/10.1080/01431161.2015.1051631

[18] Denu, D., Platts, P.J., Kelbessa, E., Gole T.W. and Marchant, R. (2016) The Role of Traditional Coffee Management in Forest Conservation and Carbon Storage in the Jimma Highlands, Ethiopia. Forest, Trees and Livelihoods, 25, 226-238. https://doi.org/10.1080/14728028.2016.1192004

[19] Platts, P.J., McClean, C.J., Lovett, J.C. and Marchant, R. (2008) Predicting Tree Distributions in East Africa Biodiversity Hotspot: Model Selection, Data Bias and Envelope Uncertainty. Ecological Modelling, 218, 121-134. https://doi.org/10.1016/j.ecolmodel.2008.06.028

[20] Luedeling, E., Kindt, R., Huth, N.I. and Koenig, K. (2013) Agroforestry Systems in a Changing Climate-Challenges in Projecting Future Performance. Current Opinion in Environmental Sustainability, 6, 1-7. https://doi.org/10.1016/j.cosust.2013.07.013

[21] Evans, J.M., Fletcher, R.J. and Alavalapati, J. (2010) Using Species Distribution 
Models to Identify Suitable Areas for Biofuel Feedstock Production. GCB Bioener$g y$, 2, 63-78. https://doi.org/10.1111/j.1757-1707.2010.01040.x

[22] Phillips, S.J., Dudik, M. and Schapire, R.E. (2004) A Maximum Entropy Approach to Species Distribution Modeling. Proceedings of the 21 st International Conference on Machine Learning, Banff, 4-8 July 2004, 83. https://doi.org/10.1145/1015330.1015412

[23] Phillips, S.J., Anderson, R.P. and Schapire, R.E. (2006) Maximum Entropy Modeling of Species Geographic Distributions. Ecological Modelling, 190, 231-259. https://doi.org/10.1016/j.ecolmodel.2005.03.026

[24] Platts, P.J., Omeny, P.A. and Marchant, R. (2014) AFRICLIM: High-Resolution Climate Projections for Ecological Applications in Africa. African Journal of Ecolo$g y$, 53, 103-108. https://doi.org/10.1111/aje.12180

[25] Odeny, D., Karanja, F., Mwachala, G., Pellikka, P., Platts, P. and Marchant, R. (2018) Comparison and Prediction of the Aboveground Carbon Storage in Croplands on the Inhabited Slopes of Mount Kilimanjaro (Tanzania) and Taita Hills (Kenya). Journal of Geographic Information System, 10, 415-438. https://doi.org/10.4236/jgis.2018.104022

[26] Knight, R.J. and Campbell, C.W. (1999) Ecological Adaptation and the Evolution of Modern Avocado Cultivars. Revista Chapingo Serie Horticultura, 5, 49-54.

[27] Erdogan, E.H., Pellikka, P. and Clark, B. (2011) Impact of Land Cover Change on Soil Loss in the Taita Hills, Kenya between 1987 and 2003. International Journal of Remote Sensing, 32, 5919-5945. https://doi.org/10.1080/01431161.2010.499379

[28] Jaetzold, R. and Schmidt, H. (1983) Farm Management Handbook of Kenya, Volume II: Natural Conditions and Farm Management Information. Part A: West Kenya; Part B: Central Kenya; Part C: East Kenya. Ministry of Agriculture, Nairobi.

[29] Newmark, W. (2002) Conserving Biodiversity in East African Forests: A Study of the Eastern Arc Mountains. Springer, Berlin.

https://doi.org/10.1007/978-3-662-04872-6

[30] Pellikka, P., Lötjönen, M., Siljander, M. and Lens, L. (2009) Airborne Remote Sensing of Spatiotemporal Change (1955-2004) in Indigenous and Exotic Forest Cover in the Taita Hills, Kenya. International Journal of Applied Earth Observation and Geoinformation, 11, 221-232. https://doi.org/10.1016/j.jag.2009.02.002

[31] Thijs, K.W., Aerts, R.R., van de Moortele, P., Aben, J., Musila, W., Pellikka, P., Gulinck, H. and Muys, B. (2015) Trees in a Human-Modified Tropical Landscape: Species and Trait Composition and Potential Ecosystem Services. Landscape and Urban Planning, 144, 49-58. https://doi.org/10.1016/j.landurbplan.2015.07.015

[32] Adhikari, H., Heiskanen, J., Siljander, M., Maeda, E., Heikinheimo, V. and Pellikka, P. (2017) Determinants of Aboveground Biomass across an Afromontane Landscape Mosaic in Kenya. Remote Sensing, 9, 827. https://doi.org/10.3390/rs9080827

[33] Misana, S.B., Sokoni, C. and Mbonile, M.J. (2012) Land-Use/Cover Changes and Their Drivers on the Slopes of Mount Kilimanjaro, Tanzania. Journal of Geographical and Regional Planning, 5, 151-164. https://doi.org/10.5897/JGRP11.050

[34] Blach-Overgaard, A., Svenning, J.-C., Dransfield, J., Greve, M. and Balslev, H. (2010) Determinants of Palm Species Distributions across Africa: The Relative Roles of Climate, Non-Climatic Environmental Factors, and Spatial Constraints. Ecography, 33, 380-391. https://doi.org/10.1111/j.1600-0587.2010.06273.x

[35] Philips, O., Baker, T., Feldpausch, T. and Brienen, R. (2009) RAINFOR Field Manual for Plot Establishment and Remeasurement. 
[36] Zanne, A.E., Lopez-Gonzalez, G., Coomes, D.A., Ilic, J., Jansen, S., Lewis, S.L., Miller, R.B., Swenson, N.G., Wiemann, M.C. and Chave, J. (2009) Data from: Towards a Worldwide Wood Economics Spectrum. Dryad Digital Repository.

[37] Chave, J., Coomes, D.A., Jansen, S., Lewis, S.L., Swenson, N.G. and Zanne, A.E. (2009) Towards a Worldwide Wood Economics Spectrum. Ecology Letters, 12, 351-366. https://doi.org/10.1111/j.1461-0248.2009.01285.x

[38] Chave, J., Rejou-Mechchain, M., Burquez, A., Chidumayo, E., Colgan, M.S., Delitti, W.B.C., Duque, A., Eid, T., Fearnside, P.M., Goodman, R.C., Henry, M., Martinez-Yrizar, A., Mugasha, W.A., Muller-Landau, H.C., Mencuccini, M., Nelson, B.W., Ngomanda, A., Nogueira, E.M., Ortiz-Malavassi, E., Pelissier, R., Ploton, P., Ryan, C.M., Saldarriaga, J.G. and Vieilledent, G. (2014) Improved Allometric Models Estimate the Aboveground Biomass of Tropical Trees. Global Change Biology, 20, 3177-3190. https://doi.org/10.1111/gcb.12629

[39] Marshal, A.R., Willcock, S., Platts, P.J., Lovett, J.C., Balford, A., Burgess, N.D., Latham, J.E., Munishi, P.K.T., Salter, R., Shirima, D.D. and Lewis, S.L. (2012) Measuring and Modeling Above-Ground Carbon and Tree Allometry along a Tropical Elevation Gradient. Biological Conservation, 154, 20-33. https://doi.org/10.1016/j.biocon.2012.03.017

[40] Phillips, S.J. and Dudik, M. (2008) Modeling of Species Distributions with Maxent: New Extensions and a Comprehensive Evaluation. Ecography, 31, 161-175. https://doi.org/10.1111/j.0906-7590.2008.5203.x

[41] Garrity, D.P., Akinnifesi, F.K., Ajayi, O.C., Weldesemayat, S.G., Mowo, J.G., Kalinganire, A., Larwanou, M. and Bayala, J. (2010) Evergreen Agriculture: A Robust Approach to Sustainable Food Security in Africa. Food Security, 2, 197-214. https://doi.org/10.1007/s12571-010-0070-7

[42] Wade, A.S.I., Asase, A., Hadley, P., Mason, J., Ofori-Frimpong, K., Preece, D., Spring, N. and Norris, K. (2010) Management Strategies for Maximizing Carbon Storage and Tree Species Diversity in Cocoa-Growing Landscapes. Agriculture, Ecosystems \& Environment, 138, 324-334. https://doi.org/10.1016/j.agee.2010.06.007

[43] Nair, P.K.R., Nair, V.D., Kumar, B.M. and Showalter, J.M. (2010) Carbon Sequestration in Agroforestry Systems. Advances in Agronomy, 108, 237-307. https://doi.org/10.1016/S0065-2113(10)08005-3

[44] Platts, P.J., Gereau, R.E., Burgess, N.D. and Marchant, R. (2013) Spatial Heterogeneity of Climate Change in an Afromontane Centre of Endemism. Ecography, 36, 518-530. https://doi.org/10.1111/j.1600-0587.2012.07805.x

[45] Good, S.P. and Caylor, K.K. (2011) Climatological Determinants of Woody Cover in Africa. PNAS, 108, 4902-4907. https://doi.org/10.1073/pnas.1013100108

[46] Fourcade, Y., Engler, J.O., Rodder, D. and Secondi, J. (2014) Mapping Species Distributions with MAXENT Using a Geographically Biased Sample of Presence Data: A Performance Assessment of Methods for Correcting Sampling Bias. PLoS ONE, 9 , e97122. https://doi.org/10.1371/journal.pone.0097122

[47] Arhends, A., Rahbek, C., Bulling, M.T., Burgess, N.D., Platts, P.J., Lovett, J.C., Kindemba, V.W., Oweni, N., Sallu, A.N., Marshall, A.R., Mhoro, B.E., Fanning, E. and Marchant, R. (2010) Conservation and the Botanist Effect.

[48] Adisoma, G.S. (1993) The Application of the Jackknife in Geostatistical Resource Estimation: Robust Estimator and Its Measure of Uncertainty. The University of Arizona, Tucson. 